\title{
Sistema de control del tiempo de recorrido de las unidades de transporte urbano, usando tecnología Web
}

\author{
System of control of the time of journey of the units of \\ transport urban, using technology Web \\ Rossangela Carpio Ojeda*
}

http://dx.doi.org/10.21503/CienciayDesarrollo.2010.v11.04

\section{RESUMEN}

Actualmente existen diversos sistemas de monitoreo de transporte urbano, basados en tecnologías de última generación, pero de elevado costo. Para resolver este problema se hizo uso de dispositivos electrónicos para la captación de datos con entrada LPT1 (puerto paralelo) y el uso de una tecnología para su implementación.

En este trabajo se diseñó e implementó un sistema de control de tiempo de recorrido de las unidades de transporte urbano, haciendo uso de la tecnología Web, siendo ésta las más utilizada hoy en día. Sin embargo, está orientada a un modelo de negocio, pudiendo ser utilizado no sólo para el transporte urbano, sino también para taxis y vehículos particulares, ampliándose de acuerdo con las necesidades. Finalmente, se presenta este sistema desarrollado, así como las pruebas de su funcionalidad y propuestas para extensiones del sistema.

Palabras clave: unidades de transporte, sensores, cabinas de Internet.

\section{ABSTRACT}

Actually there are several monitoring systems for urban, based on cutting edge technologies but high cost. To resolve this problem made use of electronic devices for data input capturing LPT1 (parallel port) and the use of technology for implementation.

In this paper is design and implement a Control System travel time of the Urban Transport Units, using Web technology, this being the most used today. However, it is oriented towards a business model can be used not only for urban transport, but also for extending taxis and private cars according to needs. Finally, this system has developed and demonstrated its functionality and proposals for system extensions.

Key words: units of transport, sensors, booths of Internet

* Alumna de la Escuela Académico-Profesional de Ingeniería de Sistemas e Informática, Filial Arequipa. 


\section{INTRODUCCIÓN}

La ciudad de Arequipa cuenta con una red vial de $1750 \mathrm{~km}$ de extensión; esta red vial está conformada por la red nacional, departamental y vecinal (metropolitana). En ella se concentra el segundo mayor parque automotor de Perú (después de Lima), con un tamaño de 130 000 vehículos aproximadamente, según los estudios de "EMBARQ", compuesto por $86 \%$ de medios de transporte urbano, incluyendo $3 \%$ de vehículos menores (motos), 10\% de medios de transporte de carga (camiones, remolques), y $4 \%$ de transporte interprovincial (ómnibus).

El control de tiempo de recorrido es muy importante para las unidades de transporte urbano, por tal motivo, cada vez que un vehículo no realiza la marcación, el tiempo de recorrido fijado no es adecuado al servicio.

En vista de esta situación, varios autores han buscado darle la más óptima solución. Backhoff, Miguel, y Paulino Juan Carlos hicieron una publicación (1) sobre el SIGET (Sistema de Información Geoestadística para Transporte), el cual se resume en diseñar, estructurar e implantar un sistema informático eficiente, versátil y sencillo, para el registro, análisis y representación de la información geográfica y estadística asociada al sistema de transporte.

Sin embargo, existen sistemas basados en tecnología GPS, la cual es usada primariamente como una herramienta para determinar la localización exacta de un lugar sobre la superficie terrestre, pero, además, puede proporcionar información sobre tiempo $y$ velocidad de objetos en movimiento, lo que le permite actuar también como un sistema de navegación por radio. Los receptores usan los datos transmitidos para calcular posiciones tridimensionales (latitud, longitud y altitud) de la antena del receptor. (2)
El sistema desarrollado trata sobre el control de tiempo de recorrido de las unidades de transporte urbano, siendo este muy importante para evitar irregularidades en el proceso de marcado, como adelanto o retraso en el momento del registro.

Al momento de realizar la marcación, la persona a cargo está expuesta a muchos peligros, como atropello o puede lastimarse con alguna caída. Frente a esta realidad, la implementación de un sistema de control de tiempo de recorrido de unidades de transporte urbano es una solución a estos problemas; muy aparte, permite la optimización del registro de tiempo de cada una de las unidades.

\section{Problema de la investigación}

¿Se podrá llevar un control de tiempo de recorrido de las unidades de transporte urbano en tiempo real, de tal forma que se pueda minimizar la inadecuada marcación del tiempo en los puntos de control por parte de las unidades de transporte urbano, y gozar de mayor confiabilidad en los registros de marcado?

\section{Objetivo de la investigación}

Desarrollar un sistema para el control de tiempo de recorrido de las unidades de transporte urbano, en tiempo real.

\section{Justificación e importancia}

El uso de este sistema de control de tiempo de recorrido es muy importante, porque hace que el servicio brindado por las unidades de transporte urbano sea adecuado, sirviendo de beneficio a la propia línea y a la colectividad.

El sistema de control de tiempo de recorrido, mejorará el control de sus unidades y el tiempo de recorrido que las diversas líneas emplean al brindar su servicio. 


\section{MATERIAL Y MÉTODO}

\section{Descripción de la solución}

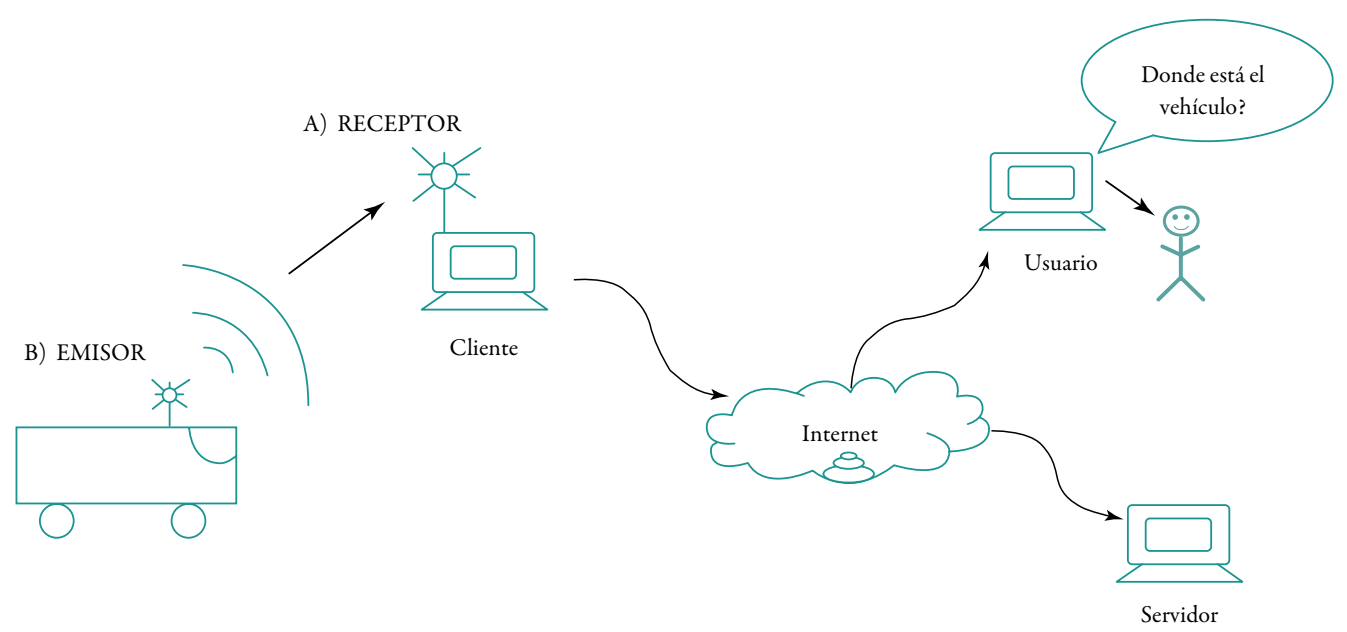

Figura 1. Esquema conceptual

A) Emisor: Se encuentra ubicado en el vehículo de transporte, al pasar por el punto de marcación; presionando un botón, éste transmitirá una señal para poder ser registrado.

B) Receptor: Se encuentra ubicado en un punto específico, en este caso en una cabina de internet (Cliente - App1). Se encargará de capturar la señal enviada por el emisor y mostrarla en la PC a la que se encontrará conectado.

Una vez capturada la señal y registrada en la PC del cliente, la información dada será enviada a la WEB (internet), siendo enviada al servidor (App2) para su mejor archivo.

Finalmente, llegará la información ya procesada al usuario, donde éste podrá saber en qué lugar se encuentra el vehículo, pudiendo generar un reporte al final del día para el control de tiempo de recorrido de cada vehículo.

\section{Requisitos Funcionales}

Tabla 1. Tabla de requisitos funcionales

\begin{tabular}{cl} 
CÓDIGO & \multicolumn{1}{|c}{ DESCRIPCIÓN } \\
\hline RF01 & Registrar usuario \\
RF02 & Registrar tiempo de paso \\
\hline RF03 & Visualizar el tiempo registrado \\
RF04 & Buscar registros \\
\hline RF05 & Generar reportes \\
\hline
\end{tabular}

RF01: Registrar usuario. El sistema permitirá registrar el nombre y password del usuario, para poder tener acceso.

RF02: Registrar tiempo de paso. El sistema permitirá registrar el tiempo en el que pasó el vehículo por el punto de control.

RF03: Visualizar el tiempo registrado. Visualizar el tiempo en el que pasó por cada punto de control en el recorrido.

RF04: Buscar Registros. El sistema permitirá al usuario realizar búsquedas de registros por diversos criterios.

RF05: Generar Reportes. El sistema permitirá al usuario generar reportes diversos de acuerdo con los contenidos predefinidos. 
Requisitos no funcionales

\section{Tabla 2. Tabla de requisitos no funcionales}

\begin{tabular}{|c|c|}
\hline CÓDIGO & DESCRIPCIÓN \\
\hline RNF01 & $\begin{array}{l}\text { Contar con dispositivos de lectura } \\
\text { de Identificación }\end{array}$ \\
\hline RNF02 & $\begin{array}{l}\text { Contar con equipos de transmisión } \\
\text { inalámbrica }\end{array}$ \\
\hline
\end{tabular}

RNF01: Contar con dispositivos de lectura de identificación. Son dispositivos, los cuales identificarán la señal enviada para que pueda ser registrado el tiempo en la Pc.

RNF02: Contar con equipos de transmisión inalámbrica. Se cuenta con dos sensores, un emisor y un receptor.

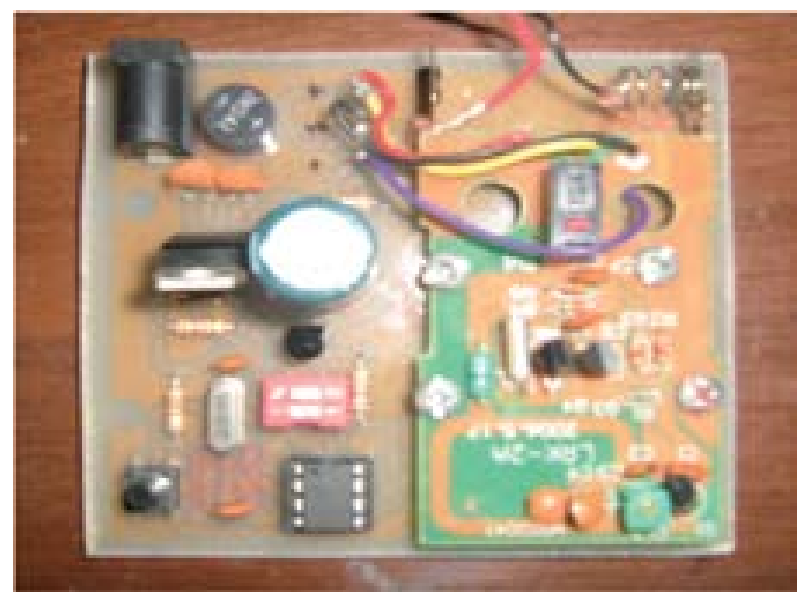

En las figuras 2 y 3 vemos dos tipos de circuito. El primero estará ubicado en el vehículo, y se encarga de enviar la señal para realizar la marcación de tiempo, en tanto que el segundo se hallará ubicado en la cabina de internet; se encarga de recepcionar la señal y enviarla a la PC mediante puerto LPT1 (puerto paralelo), para ser enviada vía Web a la central de vehículos.

$\mathrm{Al}$ ingresar al sistema, primero debemos ingresar los vehículos que estarán disponibles para brindar su servicio; una vez registradas las unidades de transporte, podremos iniciar con el control de marcación de tiempo de acuerdo con su ruta.

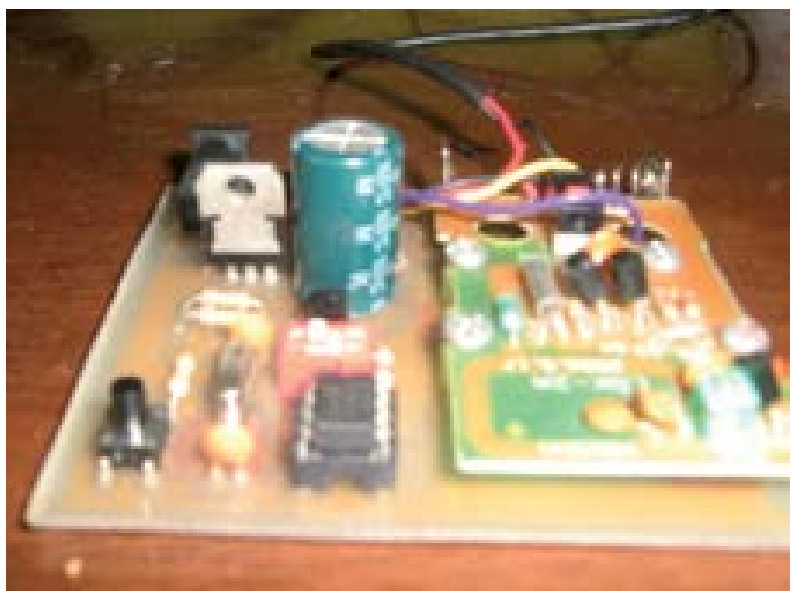

Figura 2. Circuito emisor
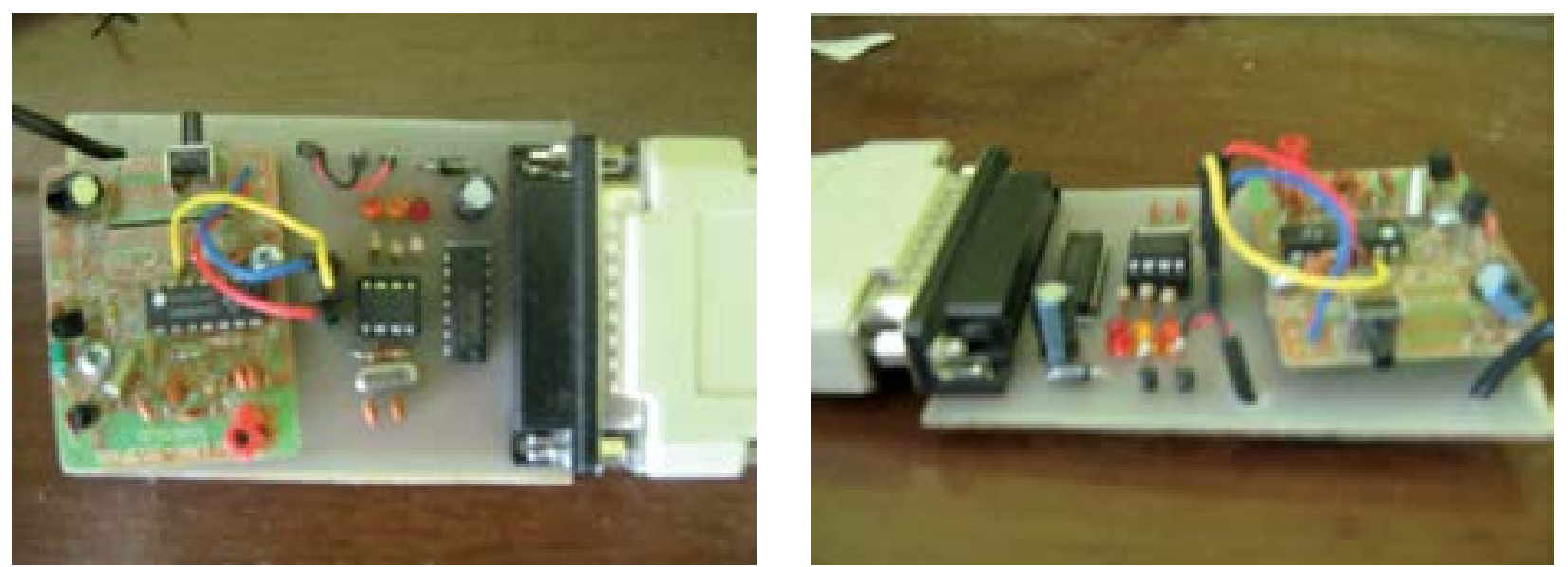

Figura 3. Circuito receptor 


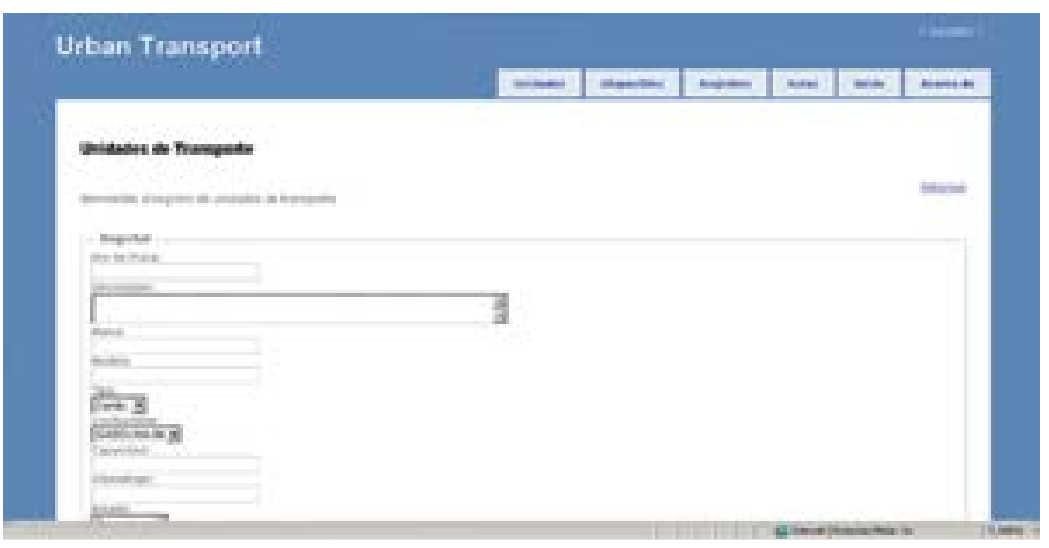

Figura 4. Interfaz de ingreso de unidades.
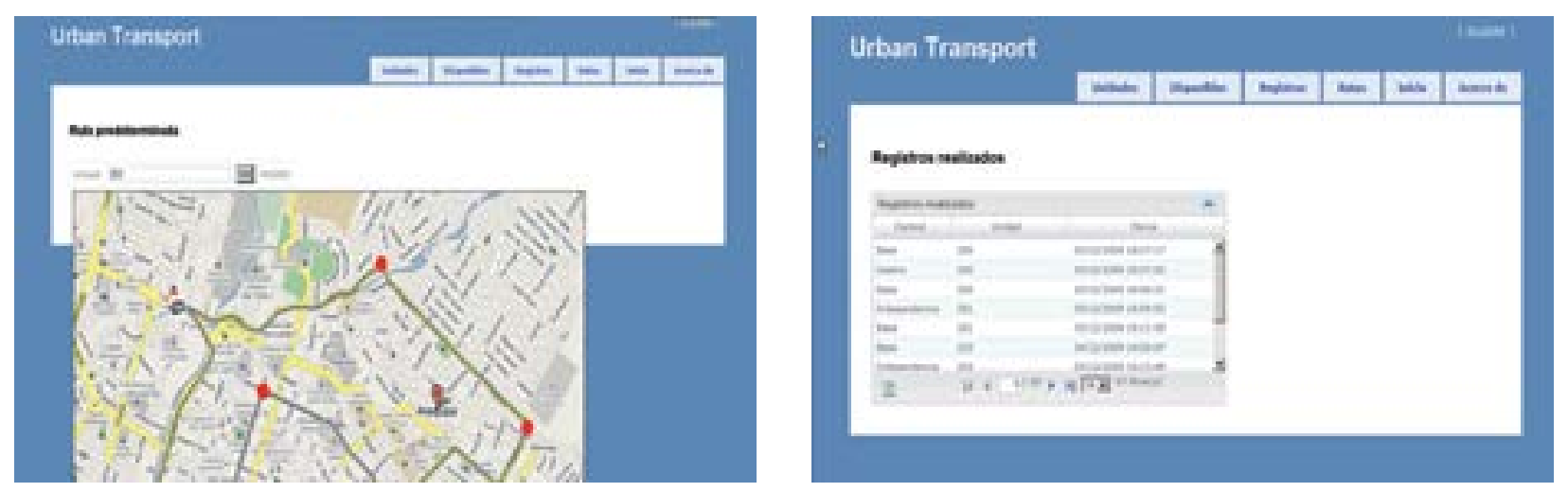

Figura 5. Interfaces de registros de marcación.

Una vez realizada la marcación, esta es registrada y mostrada en una tabla, y, sobre todo, se puede visualizar en tiempo real el recorrido del vehículo según el gráfico de ruta, pudiendo ingresar el id del vehículo para visualizar su ubicación.

\section{RESULTADOS}

Definir una ruta con seis puntos de lectura. Se establecerá un recorrido que deberán seguir los vehículos o unidades de transporte disponibles, en el cual habrá seis puntos de lectura o control, donde realizarán su marcación de tiempo.

\section{Emular los vehículos en tránsito por una} ruta de lectura. En los seis puntos de lectura

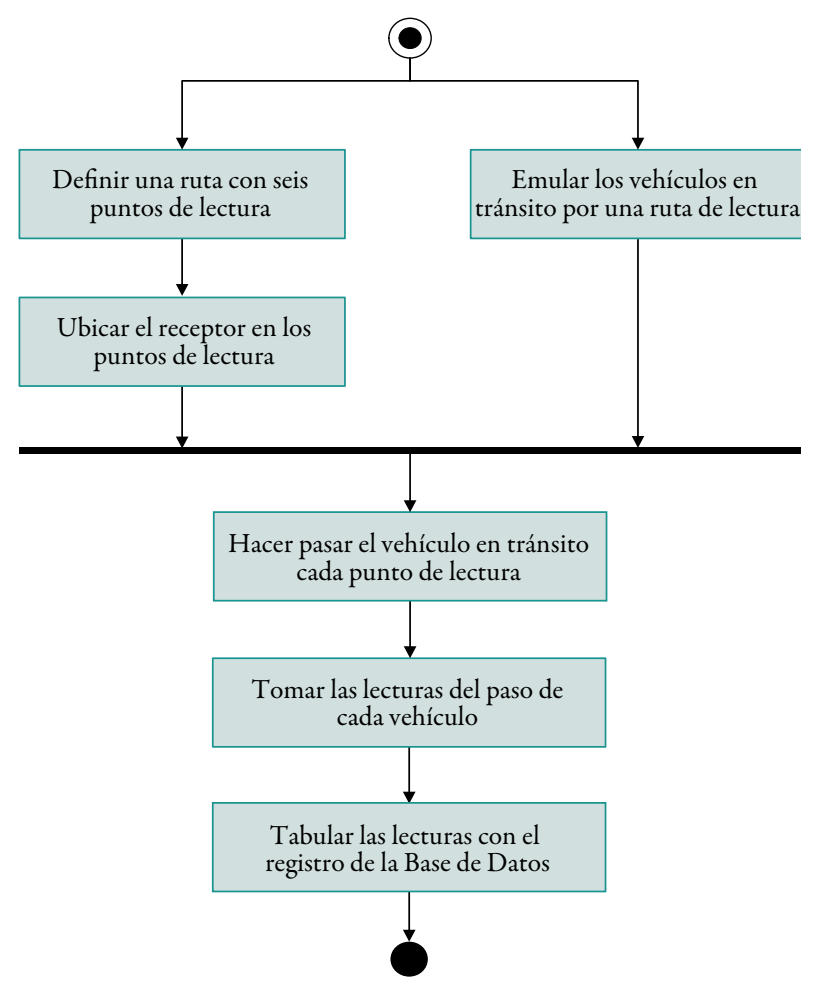

Figura 6. Diagrama de experimento. 
o control ubicados en la ruta, los vehículos deberán enviar una señal para poder realizar una marcación de tiempo. El vehículo disponible poseerá un circuito emisor, el cual usará para realizar la marcación.

Ubicar el receptor en los puntos de lectura. Cada punto de lectura tendrá un circuito receptor, el mismo que tendrá la función de capturar la señal y enviarla mediante la Web al servidor. Este receptor estará conectado en una PC que se encuentre en red.

\section{Hacer pasar el vehículo en tránsito por} cada punto de lectura. El vehículo, una vez en ruta, deberá pasar por varios puntos de lectura para llevar un control de su tiempo de marcación, enviando una señal con el circuito emisor.

Tomar las lecturas de paso de cada vehículo. El vehículo al pasar por cada punto de lectura, deberá enviar una señal, la cual será capturada por el circuito receptor, registrando la hora y fecha de paso del vehículo por ese punto en el servidor. Este solo aspecto nos permitirá obtener reportes de tiempo de recorrido por cada vehículo para un mejor control.

\section{- Tabular las lecturas con el registro de} la base de datos. Al recibir la señal en el punto de lectura esta será subida a la Web y enviada al servidor, el cual cuenta con una base de datos donde los registros realizados son almacenados, permitiendo de este modo calcular el tiempo de demora de punto a punto.

Se logró implementar satisfactoriamente el sistema, realizando todo lo propuesto a tiempo real y reduciendo las posibilidades de alteración en la marcación de tiempo por parte de las unidades de transporte.

\section{CONCLUSIONES}

Se establecieron los requisitos indispensables para la implementación del sistema para el control de tiempo de recorrido de unidades de transporte.

Adquiriendo el equipo necesario para el funcionamiento, se logró la construcción del sistema para el control de tiempo de recorrido de unidades de transporte, optimizando el tiempo de recorrido por cada punto.

Se analizó y representaron las peculiaridades del problema materia de estudio, lo cual permitió elaborar una propuesta de solución basada en tecnologías Web.

Se logró asimismo, determinar el tiempo real de la marcación del paso de las unidades de transporte por los puntos de control.

Se minimizó el fraude en el momento de la marcación, y se obtuvo mayor fiabilidad en los registros de marcación durante el recorrido.

Fue satisfactorio el funcionamiento del Sistema para el control de tiempo de recorrido de unidades de transporte, en tiempo real, permitiendo visualizar el recorrido y ubicación de la unidad de transporte.

\section{TRABAJOS FUTUROS}

Extender los estudios expuestos en éste proyecto, al estudio de la planificación de tránsito de las unidades de transporte urbano.

Ampliar el modelo dinámico, mostrado en 
el sistema para un mejor control de tiempo de recorrido de las unidades de transporte urbano.

Emplear el modelo de negocio en el otorgamiento de licencias de funcionamiento de las cabinas de internet.

Ampliar el estudio de los registros de información para determinar los patrones de marcado.

\section{REFERENCIAS BIBLIOGRÁFICAS}

1. Backhoff, Miguel, Paulino Juan Carlos. Publicación Técnica No. 207, en: bttp:// boletin.imt.mx/publicaciones/pubtec/pt207. pdf. México, 2002, 103pp

2. GPS Timble. En: bttp://www.trimble.com gps/index.shtm

3. José Emilio Labra Gayo. “Tecnologías Web”, en: bttp://petra.euitio.uniovi.es/ labra cursos/Doctorado03/Doctorado03Lenguajes. pd). Oviedo, 67pp.

4. Marc Ralita Álvarez. "Sensores inalámbricos", en: bttp://www.epsc.upc.edu/projectes/ed SED/projectes_aplicacio/TFC/M_Ralital PFC_M_Ralita_Presentacio.pd). 26pp.

5. Zara Hormazábal. Evolución de la Web, en: bttp://www.slideshare.net/zarabeatriz/clase2-evolucion-de-la-web. 2009

6. Vicente Trigo Aranda. "Historia y evolución de Internet", en: bttp://www.acta.es articulos_mf/33021.pds. 